\title{
O Papel das Propostas de Atividades On-Line nas Disciplinas Semipresenciais de Línguas da UFC Virtual ${ }^{1}$
}

\author{
The Role of Online Activity Proposals in Semi-Distance \\ Language Courses at UFC Virtual
}

\author{
Júlio ARAÚJO * \\ Samuel de Carvalho LIMA **
}

Resumo: A Universidade Federal do Ceará, por meio do Instituto UFC Virtual e em parceria com a Universidade Aberta do Brasil (UAB), oferece, entre outros cursos semipresenciais, o de Letras/Inglês e o de Letras/Português, constituídos por propostas de atividades on-line. Por entendermos que as atividades on-line podem ser responsáveis pela organização de princípios e pedagogias com foco na implementação das tecnologias da web (SALMON, 2002), o nosso objetivo neste trabalho é o de analisar o papel das propostas de atividades on-line nas disciplinas semipresenciais de línguas da UFC Virtual, tendo em vista as potencialidades de interatividade da web e os letramentos atualizados nesse contexto. Nosso recorte teórico-metodológico compreendeu a realização de uma pesquisa exploratória, descritiva e predominantemente qualitativa, embasada nas concepções de Shetzer e Warschauer (2000), Salmon (2002), entre outros autores. A investigação

${ }^{1}$ Agradecemos ao CNPq pelo apoio dado à nossa pesquisa.

* Pós-Doutorado em Linguística Aplicada pela Universidade Federal de Minas Gerais (2011). Professor e Pesquisador do Programa de Pós-Graduação em Linguística (PPGL) da Universidade Federal do Ceará. Contato: araujo.ufc@gmail.com

** Doutorando em Linguística pela UFC com bolsa do CNPq. Atualmente é professor de Língua Inglesa do Instituto Federal de Educação, Ciência e Tecnologia do Rio Grande do Norte (IFRN). Contato: samclima@gmail.com 
resultou na categorização de 4 tipos de atividades on-line praticadas nas disciplinas Lingua Inglesa 2A: compreensão e produção oral e Leitura e produção de textos acadêmicos. Ao realizarmos essa categorização, podemos observar as práticas e as habilidades que estão sendo, potencialmente, mediadas por essas atividades on-line, o que reflete o seu papel nesse contexto.

Palavras-chave: Atividades on-line; Ensino de línguas; UFC Virtual.

Abstract: The Federal University of Ceará, through the UFC Virtual Institute and in partnership with the Open University of Brazil (UAB), offers, among other semi-distance courses, the Letters/English and the Letters/Portuguese courses, consisting of online activity proposals. As we understand that the online activities may be responsible for organizing principles and pedagogies with a focus on web technology implementation (Salmon, 2002), our aim in this paper is to analyze the role of the online activity proposals in semi-distance language courses at Virtual UFC, considering the web interactivity potential updated in this context. Our theoretical and methodological approach consisted of the accomplishment of an exploratory, descriptive and predominantly qualitative research, grounded in Shetzer and Warschauer (2000), Salmon (2002), among other authors' conceptions. The investigation resulted in the categorization of 4 types of online activities practiced in English Language 2A: oral comprehension and production and Reading and writing academic texts courses. In making this categorization, we can observe the practices and skills that are potentially mediated by these online activities, and it reflects their role in this context.

Key-words: Online activities; Language teaching; UFC Virtual.

\section{Considerações iniciais}

O ensino-aprendizagem de línguas mediado pelas novas tecnologias digitais, sobretudo a web, possibilita mudanças de comportamento dos sujeitos envolvidos nesse processo através das múltiplas interações que podem ser realizadas nos ambientes virtuais (de aprendizagem), aprimorando as habilidades linguísticas dos estudantes (LAMY; GOODFELLOW, 1999; WARSCHAUER, 1999; 
BASTOS, 2003; YUAN, 2003; QUEIROZ, 2004; BUZATO, 2008; 2009; WARSCHAUER; WARE, 2008; PAIVA, 2008; PAIVA; RODRIGUES-JÚNIOR, 2009).

No contexto de Educação a Distância (Ead), as propostas de atividades a serem realizadas são, muitas vezes, responsáveis pela mediação dos conhecimentos que são trabalhados nos cursos e se encontram on-line nos ambientes virtuais de aprendizagem para a realização das interações que possibilitem o seu cumprimento.

Levando isso em consideração, levantamos a seguinte indagação: qual o papel das atividades on-line propostas nos cursos semipresenciais de línguas do Instituto UFC Virtual? Para respondermos a essa questão, objetivamos apresentar o resultado da análise que derivou em uma categorização das propostas de atividades presentes nas disciplinas Lingua Inglesa 2A: compreensão e produção oral e Leitura e produção de textos acadêmicos dos cursos semipresenciais Letras/Inglês e Letras/Português, respectivamente, ofertados pela Universidade Federal do Ceará, em parceria com o Instituto UFC Virtual e a Universidade Aberta do Brasil (UAB). Nossa categorização, que emergiu da análise dos dados, manifesta-se em função das habilidades que estão subjacentes às orientações presentes nos enunciados das atividades on-line propostas.

Para dar corpo a essa reflexão, organizamos as informações retóricas do artigo da seguinte maneira: apresentamos as bases teóricas e metodológicas de nossa investigação; esses aspectos são seguidos pela síntese de nossa elaboração, resultante da categorização, em que documentamos com exemplos de orientações encontradas nas atividades on-line e a discussão de suas implicações; por fim, concluímos este trabalho com algumas considerações relativas ao papel das atividades on-line no ensino de línguas mediado pelas novas tecnologias digitais.

\section{Aspectos teórico-metodológicos}

De acordo com Salmon (2002), as atividades on-line podem ser responsáveis pela organização de princípios e pedagogias com foco na implementação das tecnologias da web. Se planejadas eficientemente, elas podem se constituir de propostas de atividades que possibilitam a realização de uma aprendizagem ativa e participativa. Além disso, também compreendemos que essas atividades podem ser consideradas 
"uma estratégia metodológica de uso do potencial dos ambientes virtuais de aprendizagem e dos recursos colaborativos da web 2.0" (ARAÚJO JR., 2008, p. 34).

No contexto de ensino-aprendizagem de línguas na web, acreditamos que as atividades on-line podem, pelo menos em potencial, desenvolver habilidades múltiplas, levando em consideração a capacidade de interatividade que pode ser atualizada nos ambientes virtuais. Para a nossa proposta de análise e categorização das atividades on-line, intentamos, portanto, estabelecer uma relação entre atividades on-line e as habilidades potencialmente desenvolvidas, aproximando, sempre que possível, as orientações das atividades on-line com as habilidades para expressar signos de forma bem sucedida na web (letramento digital), propostas por Shetzer e Warschauer (2000), que podem ser contempladas no quadro a seguir:

Quadro 1 - Habilidades para expressar signos de forma bem sucedida na web (letramento digital) propostas por Shetzer e Warschauer (2000)

\begin{tabular}{||l|l|}
\hline \multicolumn{1}{|c|}{ HABILIDADES } & \multicolumn{1}{c|}{ DESCRIÇÃO } \\
\hline Comunicação & $\begin{array}{l}\text { Contatar indivíduos ou grupo de indivíduos } \\
\text { selecionando a tecnologia apropriada aos seus } \\
\text { propósitos comunicativos }\end{array}$ \\
\hline Construção & $\begin{array}{l}\text { Criar e administrar páginas e sites na web, } \\
\text { bem como combinar efetivamente o texto } \\
\text { com outras mídias em formato hipertextual }\end{array}$ \\
\hline Pesquisa & $\begin{array}{l}\text { Localizar, organizar e fazer uso das } \\
\text { informações presentes na web, citando e } \\
\text { dando créditos às fontes. }\end{array}$ \\
\hline
\end{tabular}

Para o cumprimento de nosso objetivo, realizamos, portanto, uma pesquisa exploratória, descritiva e de cunho predominantemente qualitativo, acompanhando os seguintes procedimentos: 1) acessamos o Solar, Ambiente Virtual de Aprendizagem (AVA) da Universidade Federal do Ceará; 2) localizamos as propostas de atividades das disciplinas Lingua Inglesa 2 A: compreensão e produção oral e Leitura e produção de textos acadêmicos; 3 ) categorizamos as atividades on-line em função das habilidades comunicação, construção ou pesquisa, tendo em vista a 
atualização das potencialidades de interatividade da web por essas atividades.

Considerando os objetivos desta investigação, procedemos à categorização das atividades on-line, isto é, suas orientações, no sentido de oferecermos um mapeamento da relação existente entre as habilidades do letramento digital propostas por Shetzer e Warschauer (2000) e as atividades on-line que analisamos. Abaixo, disponibilizamos uma figura por meio da qual o leitor pode visualizar melhor nossa tentativa de categorização das atividades on-line. Esse exercício de categorizar os dados, reconhecemos, não está completo e poderá, em estudos futuros, passar por melhoras.

Figura 1 - Categorização provisória das atividades on-line

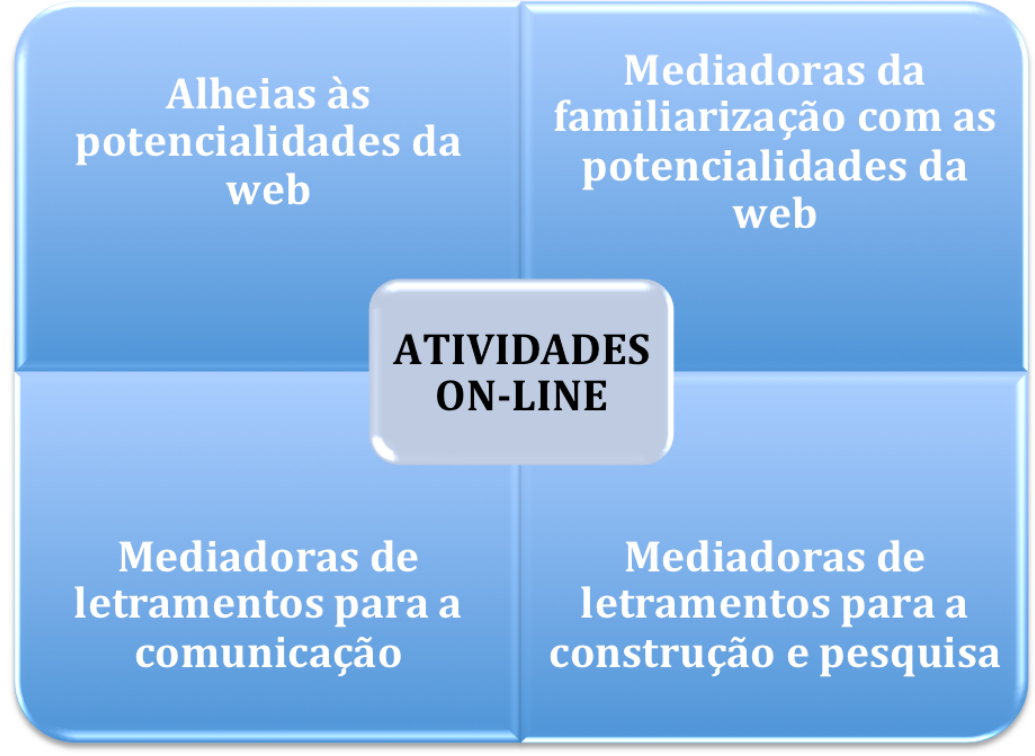

Nas seções posteriores, como demonstramos adiante, apresentamos a síntese de nossa categorização, composta de exemplos de orientações das propostas de atividades encontradas nos dados. Salientamos que o exercício de categorização é resultante de informações emergentes dos próprios dados. 


\section{Propostas de atividades on-line alheias às potencialidades de interatividade da web}

O primeiro tipo de atividades on-line encontrado é constituído por propostas que permitiram a nossa interpretação e categorização por atividades on-line alheias às potencialidades da web. Elas têm seu foco nos conteúdos de vocabulário e de gramática, apresentando-se como realizadora de um estudo automonitorado, atualizando, em potencial, a aprendizagem autodirigida (AMARAL; COSTA AMARAL, 2008). Com sua configuração constituída por propostas relativamente simplificadas, com orientações breves, seu maior interesse está ligado ao padrão formal da língua em estudo.

Sendo assim, a única interação possível a ser cumprida se conforma na relação entre os alunos e a proposta de atividade propriamente dita. Esse tipo de atividade promove uma reflexão em nível elementar, não deixando abertura para uma atitude autônoma e criativa em relação às escolhas linguísticas dos sujeitos, que não são possibilitados de tentar se aventurar com um repertório próprio, ou instigado pelo nível de dificuldade da atividade. Sua apresentação também nos provoca certa familiarização com as atividades presentes em livros didáticos de cursos regulares de línguas na modalidade presencial. A seguir, disponibilizamos exemplos de orientações presentes nas atividades on-line dessa categoria:

1) Complete the sentences with the verb wear in the present continuous form. Use contraction forms if possible. ${ }^{2}$ (Solar, UFC)

2) Write the sentences in the negative form. Use the contraction form subject + verb + not. $^{3}$ (Solar, UFC)

\footnotetext{
${ }^{2}$ Tradução livre: Complete as frases com o verbo vestir na forma do presente contínuo. Use formas contraídas se possível.

${ }^{3}$ Tradução livre: Escreva as frases na forma negativa. Use a forma contraída sujeito + verbo + não).
} 
Os exemplos acima apontam para um mero exercício de linguagem cuja finalidade maior não é exatamente o da interação humana. Por se tratar de um curso de graduação semipresencial (com maior parte das atividades on-line), julgamos que esse tipo de atividade on-line deixa de aproveitar uma das maiores possibilidades da web: a interação. $\mathrm{O}$ intercâmbio virtual, sobretudo o que se processa na web 2.0, põe-nos diante de situações autênticas de interação humana, logo, atividades como as ilustradas acima poderiam se servir de excertos autênticos. Como também mostra Araújo Jr. (2008), esse tipo de atividade on-line não se constitui uma estratégia metodológica de uso do potencial dos ambientes virtuais de aprendizagem, sobretudo, porque não suscita práticas de leitura e escrita nos variados ambientes oportunizados pela web. Em função disso, e com base no que propõem Shetzer e Warschauer (2000), categorizamos essas ocorrências do corpus de atividades on-line alheias às potencialidades à interatividade da web, pois elas não permitem o estabelecimento de relações entre o conteúdo e as habilidades de comunicação, construção ou pesquisa.

\section{Propostas de atividades on-line mediadoras da familiarização com as potencialidades da web}

Quanto ao segundo tipo de atividades on-line encontradas, elas são constituídas por propostas que permitiram a nossa interpretação e categorização por atividades on-line mediadoras da familiarização com as potencialidades da web. Elas podem ter seu foco:

a) nos conteúdos de compreensão auditiva e de pronúncia de fonemas, palavras, frases e diálogos, apresentando-se, também, como realizadora de um estudo automonitorado, atualizando, em potencial, a aprendizagem autodirigida (AMARAL; COSTA AMARAL, 2008), quando levamos em consideração a disciplina Lingua Inglesa 2 A: compreensão $e$ produção oral;

b) ou nas práticas já realizadas em outros contextos particulares, que não sejam os virtuais, como no caso da prática social de leitura e escrita de textos pertencentes aos gêneros acadêmicos, tais como resumos, resenhas e artigos, que pode ser realizada em uma sala de aula no sistema presencial de 
ensino que não se utilize do potencial de interatividade da web, por exemplo, quando levamos em consideração a disciplina Leitura e produção de textos acadêmicos.

Seguem-se exemplos de atividades dessa categoria advindo das duas disciplinas investigadas.

3) Click on the the PLAY button to hear the words. Then click on the correct answer. ${ }^{4}$

Figura 2 - Ilustração de atividade on-line da disciplina Lingua Inglesa 2A: compreensão e produção oral

Clothing

Click on the PLAY button to hear the words. Then click on the correct answer.

$\Leftrightarrow 1 / 20 \Rightarrow$

Show All Questions

O exemplo acima demonstra a proposta de algumas atividades on-line que se enquadram na categoria atividades on-line mediadoras da familiarização com as potencialidades da web. Este tipo de atividade assume uma configuração muitas vezes constituída por propostas relativamente simplificadas, com orientações breves, cujo maior interesse geralmente está ligado ao padrão formal da língua em estudo. O que observamos é que essas atividades on-line, embora apresentem aspectos técnicos, como uma interface que sugere cliques em botões digitais e o uso constante do mouse e do teclado pelo estudante, apresentam

${ }^{4}$ Tradução livre: Clique no botão PLAY para ouvir as palavras. Depois clique na resposta correta. 
também uma única interação possível a ser realizada entre alunos e a proposta de atividade propriamente dita, promovendo uma reflexão em nível elementar, não deixando abertura para uma atitude autônoma e criativa em relação às escolhas linguísticas dos sujeitos, a quem não são dadas oportunidades de tentar se aventurar com um repertório próprio, ou instigado pelo nível de dificuldade da atividade.

Quando é o caso da disciplina Leitura e produção de textos acadêmicos, as atividades on-line dessa categoria, embora se utilizem dos recursos da web para a disponibilidade dos textos a serem lidos e a postagem da produção escrita, resultante da reflexão de leituras, no portfólio, também não atualizam o potencial de interações sociais relevantes, compreendidas pela dimensão da comunicação. Vamos o exemplo abaixo.

4) Leia o artigo [... ] e selecione as definições de gêneros e sequências textuais que você julga mais interessantes. Com base nos conceitos selecionados, escreva um pequeno texto, de no máximo duas páginas, articulando e comentando sobre os temas Gêneros Textuais e Sequências Textuais. Os trechos selecionados devem aparecer em seu texto em forma de citações diretas, indiretas e citações de citações (siga as normas da ABNT). Não se esqueça de apresentar as referências no final de seu texto. (Solar, UFC)

Observamos que a proposta acima, um exemplo de tantas dessa natureza, orienta os alunos para a produção exclusiva de texto verbal, sem qualquer integração com outras modalidades, o que, também, não possibilita uma aproximação desse tipo de atividade on-line com a dimensão da construção de caráter multimodal.

No entanto, embora não apresentem uma relação direta com as habilidades de comunicação, construção e pesquisa (SHETZER; WARSCHAUER, 2000), as atividades on-line mediadoras da familiarização com as potencialidades da web oportunizam aos alunos: 1) a navegação simultânea em ambientes virtuais distintos, atualizados em diferentes páginas da internet; 2) o auxílio na interação com os variados recursos multimodais de forma integrada, tais como o texto verbal, os recursos de áudio e vídeo, ainda que não medeiem a habilidade de construção de textos multimodais pelos alunos; 3) o favorecimento da familiarização com os recursos presentes em ambiente 
virtual de aprendizagem, resultantes da personalização da potencialidade da web, como o caso do portfólio.

\section{Propostas de atividades on-line mediadoras de habilidades de comunicação}

O terceiro tipo de atividades on-line encontrado é constituído por propostas didáticas que permitiram a nossa interpretação e categorização por atividades on-line mediadoras de habilidades de comunicação. Esse terceiro tipo apresenta proposta de exercícios bem mais elaborados, se comparado com as duas categorias de atividades on-line apresentadas anteriormente (atividades on-line alheias às potencialidades da web e as atividades on-line mediadoras da familiarização com as potencialidades da web).

As atividades on-line mediadoras de habilidades de comunicação suscitam diversas práticas de leitura e escrita em ambientes virtuais, dando prioridade à habilidade de comunicação. Elas oportunizam, em todas as suas propostas, o exercício efetivo da interação entre os indivíduos ou entre o grupo de indivíduos, a partir de ferramentas digitais que permitam interação síncrona, ou assíncrona, que melhor atende aos seus propósitos comunicativos e à sua flexibilidade pessoal. Além disso, elas podem ser responsáveis, pelo menos em potencial, por desenvolverem as habilidades que compreendem a participação em gêneros digitais específicos, tendo em vista uma postura ativa e significativa dos sujeitos que realizam interações com as suas propostas.

5) Caro aluno, embora esta parte venha antes das demais, essa parte somente deverá ser executada depois de concluida as outras duas. Ela traz uma atividade de interação mais livre entre você e um colega de turma através do Skype. Você deverá combinar com seu buddy um dia e hora para estar online juntos e realizarem a tarefa proposta para a aula. Lembre-se que vocês deverão gravar esse diálogo e enviar para o seu tutor. Nesta tarefa você apresentará e descreverá a sua família e perguntará sobre a família de seu colega.

Como mostramos no exemplo acima, essas atividades on-line priorizam a comunicação, respeitando as potencialidades e os limites 
dos gêneros em particular, relativamente estáveis, presentes no cotidiano ou na consciência dos sujeitos que participam de uma sociedade que realiza práticas sociais de leitura e escrita na web. Falar por meio do Skype ${ }^{5}$ hoje, tem sido uma atividade corriqueira para muitas pessoas e, portanto, estabelecer um uso pedagógico dessa ferramenta para que os alunos aperfeiçoem o inglês pareceu-nos uma estratégia que sustenta essa atividade na categoria daquelas que são mediadoras de habilidades de comunicação.

Outra ferramenta digital bastante explorada por essas categorias de atividades on-line é o fórum eletrônico, conforme mostra o exemplo seguinte:

Figura 3 - Ilustração de atividade on-line da disciplina Leitura e produção de textos acadêmicos

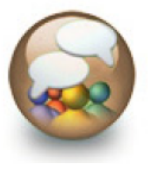

\section{Fórum}

A partir da leitura do artigo (link) "A RETÓRICA E A CIÊNCIA: DOS ARTIGOS ORIGINAIS À DIVULGAÇÃO CIENTÍFICA" tente enumerar as diferenças estilísticas e retóricas existentes entre um artigo científico original e de divulgação. Discuta com seus colegas sobre as implicações que podem ocorrer no processo de adaptação de um gênero científico para outro, quais cuidados autores e leitores devem ter ao entrar em contato com os dois gêneros científicos.

A atividade ilustrada pela figura 3 nos remete aos objetivos apontados por Freire et al. (2007), quando se referem aos cursos a distância oferecidos pelo Centro de Formação Continuada do Instituto de Estudos da Linguagem (CEFIEL): 1) a constituição de um grupo de discussão sobre as questões relevantes a respeito dos temas abordados; 2) a intensificação de trocas de mensagens, favorecendo a comunicação constante em ambientes virtuais; 3) a oportunidade de

5 Skype é um software que permite comunicação pela internet através de conexões de voz sobre IP (VoIP), permitindo comunicação de voz e vídeo grátis entre os usuários do software. 
circulação de textos, disponibilizados em ambientes virtuais diversos; 4) a promoção constante da leitura e da escrita no ambiente virtual; 5) a origem de reflexões que possibilitam a construção significativa e coletiva do conhecimento em relação aos temas abordados.

\section{Propostas de atividades on-line mediadoras de habilidades de construção e pesquisa}

As atividades on-line mediadoras de habilidades de construção e pesquisa constituem a nossa interpretação e categorização do quarto tipo de atividades on-line flagradas nos dados encontrados em nossa investigação. Por revelar-se como instrumento de avaliação, essa categoria reúne propostas de atividades mais elaboradas, suscitando diversas práticas de leitura e escrita em ambientes virtuais, dando prioridade às habilidades de construção e pesquisa.

Em relação à habilidade de construção, flagramos a mediação, em potencial, da convergência de recursos multimodais da hipertextualidade, podendo ser entendida como a integração de texto verbal com figura e/ou arquivo de áudio, bem como o armazenamento de dados oriundos dos recursos de interatividade da web ao se gravar a leitura de textos, ou o diálogo realizado através de interações entre os sujeitos. Salientamos, no entanto, que essas habilidades, potencialmente mediadas, não mantêm uma relação estreita com a de construir e administrar páginas na web, forma preconizada pela habilidade de construção proposta por Shetzer e Warschauer (2000); contudo, advogamos que eles podem ser interpretados como parte integrante de um projeto maior, que poderia resultar na construção efetiva de uma página na web, e sua posterior administração. Além disso, elas foram as habilidades emergentes dos dados de nossa análise.

Quanto à habilidade de pesquisa, as propostas de atividades dessa quarta categoria de atividade on-line sugerem orientações que oportunizam ao aluno a realização de uma pesquisa tendo como fonte primária os ambientes virtuais. Localizar, organizar e fazer uso das informações presentes na web, ao acessar ambientes virtuais específicos que trazem informações sobre distintas cidades em diferentes partes do mundo, com o objetivo de ter a proposta de atividade cumprida, constituem as habilidades básicas mediadas por esse tipo de atividades on-line. 
Abaixo, seguem exemplos de orientações presentes nas atividades on-line dessa categoria:

6) Você deverá escolher uma das figuras e escrever um texto descrevendo o que as pessoas estão fazendo. Grave esse texto e envie-o em arquivo escrito e em arquivo de áudio.

7) Na primeira atividade, você deverá acessar o site indicado e escolher três cidades para descrever a previsão do tempo indicado na data de acesso. $\mathrm{Na}$ segunda, utilizará as informações obtidas na primeira atividade e fará comparações sobre o tempo nas três cidades.

Ressaltamos que a nomenclatura das categorias que compreendem os tipos de atividades on-line encontradas nas disciplinas semipresenciais de línguas da UFC Virtual tem caráter descritivoexploratório, levando em consideração a interpretação dos dados encontrados durante a nossa investigação. Para que fosse possível essa categorização, optamos por privilegiar o que havia de maior destaque em cada atividade, compreendendo que uma atividade on-line pode apresentar propostas tão flexíveis que oportunizaria um entendimento de possíveis imbricações entre os traços presentes em mais de uma categoria acima descrita.

\section{Considerações finais}

Classificar uma atividade on-line tendo em vista uma das categorias elucidadas por este trabalho demanda um senso de percepção de diversos fatores, tais como: o propósito mais saliente da atividade on-line; os recursos tecnológicos atualizados por essas atividades; o tipo de interatividade proporcionada por esses recursos; as habilidades potencialmente desenvolvidas pelas orientações dessas atividades online, entre outros. Sendo assim, a nossa investigação serve a um propósito exploratório de análise do papel das propostas de atividades on-line nas disciplinas semipresenciais de línguas da UFC Virtual para, com base nesses primeiros achados, redirecionarmos nossa pesquisa.

Nosso artigo se limitou a descrever apenas duas disciplinas ministradas no Solar e, por isso, as conclusões não podem ser 
generalizadas para todas as atividades on-line elaboradas e publicadas nesse ambiente virtual de aprendizagem. No entanto, as conclusões já sinalizam para algumas implicações pedagógicas concernentes às atividades on-line propostas nesse contexto, que merecem ser levadas em consideração. Entendemos, por exemplo, que o conhecimento linguístico é relevante e deve ser estudado no ensino-aprendizagem de línguas em ambientes virtuais; no entanto, não é desejável que esse conhecimento seja abordado esvaziado de elementos pragmáticos que, em potencial, podem marcar e enriquecer a cena enunciativa. Assim, preencher quadros e espaços em branco para testar conhecimentos meramente linguísticos em uma atividade on-line pode ser reflexo de uma limitação do aproveitamento das inúmeras potencialidades de interatividade possibilitadas pela web.

Nesse sentido, acreditamos que os resultados que emergem dessa investigação não apenas podem lançar luzes no aspecto pedagógico do ensino-aprendizagem de línguas, como também podem trazer alguma contribuição do ponto de vista do design instrucional na medida em que, ao analisarmos as potencialidades das ferramentas disponibilizadas no Solar, podemos levantar informações relevantes para equipe que se responsabiliza pela transmutação do conteúdo impresso para o ambiente virtual de aprendizagem.

Outra implicação pedagógica que emerge desse exercício de análise diz respeito à formação de professores para a docência em ambiente digital que, como mostra Freitas (2009), é ainda algo incipiente em nosso país. O curso de Letras na modalidade semipresencial é uma licenciatura e, como tal, é um curso de formação de professores. As atividades on-line mostram que esses futuros professores de línguas podem agregar sabedores docentes próprios dos letramentos digitais, pois, na condição de alunos, participam de muitos eventos dessa natureza, como se comunicar por meio do Skype ou de fóruns eletrônicos.

Finalmente, estabelecida uma categorização baseada no que os dados da pesquisa nos demonstraram, podemos observar as práticas e as habilidades que estão sendo, potencialmente, mediadas por essas atividades on-line, como saber interagir na língua alvo, dominar habilidades de escrita acadêmica, entre outras. Percebemos que a criatividade dos responsáveis pela elaboração e oferecimento das 
atividades on-line, utilizando-se da flexibilidade dos recursos de interatividade da web, constitui agente motivador da manifestação de atividades on-line mais complexas e que demandam uma reflexão mais elaborada para a sua execução, oportunizando o desenvolvimento de inúmeras habilidades.

\section{Referências}

AMARAL, L.H.; COSTA AMARAL, C.L. Tecnologias de comunicação aplicadas à educação. In: MARQUESI, S.C.; ELIAS, V.M.S.; CABRAL, A.L.T. (Orgs.). Interações virtuais: perspectivas para o ensino de Língua Portuguesa. São Carlos: Claraluz, 2008. p. 11-20.

ARAÚJO JR, C.F. Ambientes virtuais de aprendizagem: comunicação e colaboração na Web 2.0. In: MARQUESI, S.C.; ELIAS, V.M.S.; CABRAL, A.L.T. (Orgs.). Interacõoes virtuais: perspectivas para o ensino de Língua Portuguesa. São Carlos: Claraluz, 2008. p. 21-42.

BASTOS, H.P.P. Letramento eletrônico em língua inglesa: da teoria à prática. Vértices, Campos dos Goytacazes, a. 5, n. 3, p. 23-37, 2003.

BUZATO, M.E.K. Letramentos multimodais críticos: contornos e possibilidades. Crop (FFLCH/USP), v. 12, p. 108-144, 2008.

. Letramento e inclusão: do estado-nação à era das TIC. D.E.L.T.A., v. 25, p. 1-38, 2009.

FREIRE, F.; CAVALCANTI, M.; KLEIMAN, A.; POSSENTI, S. Leitura e escrita via internet: formação de professores nas áreas de alfabetização e linguagem. Trabalhos em Linguística Aplicada, Campinas, v. 46, n. 1, p. 93-111, 2007.

FREITAS, M.T.A. A formação de professores diante dos desafios da cibercultura. In: . (Org.). Cibercultura e formação de professores. Belo Horizonte: Autêntica, 2009. p. 57-74. 
LAMY, M.; GOODFELLOW, R. "Reflective Conversation" in the virtual language classroom. Language Learning \& Technology, v. 2, n. 2, p. 43-61, 1999.

PAIVA, V.L.M.O. Internet e sistemas de busca: ampliando o universo de professores e aprendizes de língua inglesa. In: MACIEL, R.F.; ARAÚJO, V.A. (Orgs.). Ensino da língua inglesa: contribuições da Linguística Aplicada. Campo Grande: ANAES, 2008. p. 43-58.

.; RODRIGUES-JÚNIOR, A.S. Investigating interaction in an EFL online environment. Handbook of Research on E-learning methodologies for language acquisition. Hershey PA: Information Science Reference (IGI Global), p. 53-68, 2009.

QUEIROZ, E.S.C. Educação a distância: uma investigação sobre possíveis contribuições para a educação continuada de professores de língua estrangeira (inglês). Revista Brasileira de Linguística Aplicada, Belo Horizonte, v. 4, n. 2, p. 11-44, 2004.

SALMON, G. E-tivities: the key for active online learning. Northants (Inglaterra): Kogan Page, 2002.

SHETZER, H.; WARSCHAUER, M. An electronic literacy approach to network-based language teaching. In: WARSCHAUER, M.; KERN, R. (Orgs.). Network-based Language Teaching: concepts and practice. Nova York: Cambridge University Press, 2000. p. 171-185.

WARSCHAUER, M. Electronic literacies: language, culture, and power in online education. Mahwah: Lawrence Erlbaum Associates, 1999.

.; WARE, M. Learning, change, and power: competing discourses of technology and literacy. In: COIRO, J.; KNOBEL, M.; LANKSHEAR, C.; LEU, D. J. (Orgs.). Handbook of research on new literacies. New York: Lawrence Erlbaum Associates, 2008. p. 215-240.

YUAN, Yi. The use of chat rooms in an ESL setting. Computers and Composition, Nova York, v. 20, n. 2, p. 194-206, 2003. 